In view of the extract shown in Fig. 1 (ref. 3), may I suggest that the name of the British scientist, Oliver Heaviside, should be associated with this phenomenon.

Department of Physics,

T. R. KAISER

University of Sheffield, S10 2TN

Received October 15, 1973.

1 Cerenkov, P. A., Dokl. Acad. Nauk S.S.S.R., 2, 451 (1934).

2 Frank, I. M., and Tamm, I. Y., Dokl. Acad. Nauk S.S.S.R., 14, 109 (1937).

3 Heaviside, O., Electrical Papers, II, 494 (Macmillan, London, 1892) (originally published in The Electrician, 83: November $23,1888)$.

\section{Heaviside-Mallet Radiation?}

FOR those who have worked on Cerenkov radiation it is of great interest to read that Kaiser ${ }^{1}$ has unearthed a prediction of the effect by Heaviside that predates Čerenkov's early work by 46 years, and it is remarkable that apparently, this has not been pointed out before.

It would seem, however, at least from the extract quoted by Kaiser, that Heaviside did not suggest or carry out any experiments. Indeed this was virtually impossible at that time, as his paper predates the discoveries of cosmic rays and radioactivity, and there were, of course, no beams of artificially accelerated relativistic particles available at that time.

It is therefore on the theoretical side that Heaviside's work is significant and his name should thus be linked with those of Vavilov ${ }^{2}$ and of Frank and Tamm ${ }^{3}$.

Here I point out that, as far as the experimental side is concerned, it would seem rather that the credit should go to the French physicist Mallet, who, through his observations between 1926 and 1928 (refs. 4 to 6), was probably the first to study the effect always attributed to Cerenkov, a point already raised by myself ${ }^{7}$, by Mallet himself ${ }^{8}$ and by Perrin'. I therefore suggest that, for those who feel that changing established names for well known phenomena is justifiable, the title Heaviside-Mallet radiation might be more appropriate than the one put forward by Kaiser. In connection with double-barrelled titles it is of interest to note that for many years the effect has also been known as VavilovCerenkov radiation, at least within the Soviet Union.

It is not inappropriate that a French name should be associated with the effect since there is little doubt that the glow from the concentrated radioactive solutions prepared by Mme Curie ${ }^{10}$ was generated by the same mechanism; her observations took place around 1910.

This letter should not, however, be interpreted as discrediting three brilliant Nobel Prize winners, for by far the greater proportion of all theoretical work in the field has nevertheless been carried out by Russian physicists. There are sixty-two Russian references in ref. 7 alone and two other relevant sources of information, both Russian, are the treatises by Bolotovskii ${ }^{11}$ and by Zrelov ${ }^{12}$.

Nuclear Physics Division,

J. V. JeLLeY

AERE,

Harwell,

Berkshire

Received October 29; revised November 6, 1973.

${ }^{1}$ Kaiser, T. R., Nature, 247, 400 (1974).

2 Vavilov, S. I., Dokl. Akad. Nauk SSSR, 2, 457 (1934).

${ }^{3}$ Frank, I. M., and Tamm, Ig., Dokl. Akad. Nauk. SSSR, 14 [3], 109 (1937).

4 Mallet, L., C.r. hebd. Séanc. Acad. Sci. Paris, 183, 274 (1926).

5 Mallet, L., C.r. hebd. Séanc. Acad. Sci. Paris, 187, 222 (1928).

6 Mallet, L., C.r. hebd. Séanc. Acad. Sci. Paris, 188, 445 (1929).
7 Jelley, J. V., Cherenkov Radiation, and its Applications, 1 and 2 (Pergamon, London, 1958).

8 Mallet, L., C.r. hebd. Séanc. Acad. Sci. Paris, 247, 1449 (1958).

9 Perrin, F., C.r. hebd. Séanc. Acad. Sci. Paris, 247, 1450 (1958).

10 Curie, Eve, Madame Curie (Heinemann, London, 1941).

11 Bolotovskii, B. M., Usp. Fiz. Nauk SSSR, 62 [3], 201 (1957).

12 Zrelov, V. P., Cherenkov Radiation in High-Energy Physics, Part I (Israel Program for Scientific Translations Ltd, Keter Press, Jerusalem, 1970). Also AEC translation No. 7099.

\section{Alternative to Holography for Determining Phase from Image Intensity Measurements in Optics}

IN light optics and electron optics one normally measures the image intensity and attempts to infer from these measurements the object structure. In light optics these intensity measurements are insufficient to evaluate the detailed structure of the object and information on the phase of the transmitted light is of prime importance ${ }^{1}$; the interaction of the light or electrons in transmission through the object can be only satisfactorily explained by wave optics. The phase problem in optics is analogous to the X-ray diffraction phase problem, that is, whereas an object can be reconstructed from the phase information (even with incorrect amplitudes), it is not possible to define an object from amplitude measurements only ${ }^{1}$. We suggest here how a normal optical system can be used to determine both the amplitude and phase from image intensity measurements in bright-field optics. In bright-field optics, where the main (on-axis) beam is allowed to interfere with the scattered wave, the transmitted object wavefunction $\psi_{0}\left(r_{0}\right)$ can be written as

$$
\psi_{0}\left(r_{0}\right)=1+\psi_{s}\left(r_{0}\right)
$$

where $\psi_{s}\left(r_{0}\right)$ represents the effect of the object on the incident light or electron wave at the point $r_{0}=\left(x_{0}, y_{0}\right)$ in the object plane; $\psi_{\mathrm{s}}$ carries information not only on the amplitude attenuation of the wave but also phase shifts introduced by refractive index differences (potential differences in electron optics) across the object. The 1 represents the amplitude of the transmitted wave that is not scattered in the object, and this unscattered contribution will give a background in the image. The wavefunction $\psi_{0}\left(r_{0}\right)$ transmitted by the object may be subsequently affected by lens defects and restricting apertures in the optical system, particularly in electron optics, but for simplicity we shall assume that the wave at the image plane $\psi_{i}\left(r_{i}\right)$ is equivalent to $\psi_{0}\left(r_{0}\right)$. We record not $\psi_{i}\left(r_{i}\right)$ but the image intensity $\left|\psi_{\mathrm{i}}\left(r_{\mathrm{i}}\right)\right|^{2} \equiv\left|\psi_{0}\left(r_{0}\right)\right|^{2}$; the image intensity is from equation (1)

$$
\begin{aligned}
j\left(r_{\mathrm{i}}\right) & =\left|\psi_{\mathrm{i}}\left(r_{\mathrm{i}}\right)\right|^{2}=\left|1+\psi_{\mathrm{s}}\left(r_{\mathrm{i}}\right)\right|^{2} \\
& =1+2 \operatorname{Re}\left[\psi_{\mathrm{s}}\left(r_{\mathrm{i}}\right)\right]+\operatorname{Re}^{2}\left[\psi_{\mathrm{s}}\left(r_{\mathrm{i}}\right)\right]+\operatorname{Im}^{2}\left[\psi_{\mathrm{s}}\left(r_{\mathrm{i}}\right)\right]
\end{aligned}
$$

where $R e$ and $I m$ denote the real and imaginary parts of $\psi_{\mathrm{s}}$. At best, if the interaction between the light or electron wave and the object is small and the squared terms in equation (2) can be neglected, we can only determine the real part of $\psi_{\mathrm{s}}$ from image intensity measurements, and there is no direct way of evaluating the imaginary part of $\psi_{\mathrm{s}}$, hence determining both the amplitude and phase. But instead of using a normal circular aperture in the back focal plane (Fourier plane) of the objective lens, we can use a semicircular (half-plane) aperture to cut off one-half of the Fourier plane of the object wavefunction. The Fourier plane, which corresponds to the diffraction or scattering plane, displays the spatial frequencies 